\title{
PROPUESTA DE ORDENAMIENTO DEL ARBOLADO DE ALINEACIÓN MEDIANTE LA INTERVENCIÓN VECINAL EN EL PARTIDO DE QUILMES - PROVINCIA DE BUENOS AIRES - ARGENTINA
}

Gabriela Eda Campari

\begin{abstract}
Resumen: El arbolado público de alineación se encuentra condicionado por diversos conflictos derivados del crecimiento poblacional, el aumento del tránsito vehicular, los intereses inmobiliarios, las intervenciones clandestinas, el incumplimiento normativo, las cuestiones de higiene, la estética y su progresivo deterioro natural. En tal sentido el presente trabajo tiene como finalidad abordar una primera aproximación a la problemática de los árboles en las aceras de calles y avenidas de la ciudad de Quilmes, para la cual el factor antrópico es un agente de degradación del paisaje urbano cuya incidencia notable se percibe en el arbolado, constituyéndose éste en un indicador de perturbación paisajística negativa; el cual mediante una adecuada planificación y modificando esta actitud humana a través de la intervención vecinal organizada, posibilitaría gestionar en permanente valor este recurso vegetal como servicio público, patrimonio natural y cultural de la Ciudad.
\end{abstract}

Palabras clave: Arbolado de alineación; Arbolado público; Paisaje urbano; Servicio público; Patrimonio cultural; Intervención vecinal.

\section{Introducción}

El presente trabajo se realizó en base a mi tesis de graduación (CAMPARI, 2001), con el objeto de revalorar el arbolado de alineación en aceras de calles y avenidas en sus dimensiones históricas, ambientales y paisajisticas, de modo que se reincorporen al patrimonio de la ciudad de Quilmes; promover la toma de conciencia de la población sobre la importancia de un adecuado manejo del patrimonio vegetal arbóreo, sugiriendo la intervención vecinal organizada como una herramienta alternativa para el cause de la propuesta; y desarrollar un modelo de análisis e intervención en el ordenamiento del arbolado urbano de alineación para que pueda ser aplicado en otros casos de similar escala y contexto.

Se entiende por arbolado público de alineación a todos aquellos árboles, arbustos y/o palmeras existentes en las veredas de calles y avenidas, plantados en una plantera 0 cazuela en disposición alineada, pertenecientes al dominio municipal.

\section{Antecedentes del accionar social en el arbolado público} Quilmes, Partido conurbano de la provincia de Buenos
Aires, es un sitio ubicado a $34^{\circ} 50^{\prime}$ de latitud sur y $58^{\circ} 15^{\prime}$ de longitud oeste, con una superficie de $94 \mathrm{~km}^{2}$ y una población estable de 511.234 según el Censo Nacional de 1991 (ARGENTINA, 1991). Declarada ciudad en 1916, forma parte del conglomerado que se extiende al sur de la Ciudad Autóctona de Buenos Aires, sobre el eje del Área Metropolitana, encontrándose aproximadamente a $20 \mathrm{~km}$ del microcentro de la capital y a $44 \mathrm{~km}$ de la ciudad de La Plata.

Conformado por las localidades de Bernal, Ezpeleta, San Francisco Solano, Villa la Florida, Don Bosco, el Partido con ciudad cabecera en Quilmes, tiene como límite noreste el Río de La Plata, noroeste los Partidos de Avellaneda, Lanús, Berazategui y Florencio Varela, hacia el sudeste Lomas de Zamora y el Partido de Almirante Brown en el sudoeste.

Quilmes fue fundado el 14 de agosto de 1666 cuando se estableció la reducción de la Santa Cruz de Quilmes, destinada a asentamientos forzados de las poblaciones indígenas de los indios Quilmes y Acalianos. Con el objeto de conseguir resultados prácticos, facilidad de replanteo, distribución y defensa (CHUECA GOITíA, 1990:129), ni la barranca quilmeña, ni el río impidieron

\footnotetext{
1 Lic. en Planificación y Diseño del Paisaje, Docente Materia Geografía Facultad de Arquitectura, Diseño y Urbanismo Universidad de Buenos Aires, Argentina. e-mail: gecampari@yahoo.com.ar
} 
que la cuadrícula que ordenaban las Leyes de Indias se impusiera ante el trazado del sitio, hecho que resultó ser un módulo de repetición para la conformación de las ciudades como lo fue Quilmes.

La incipiente traza urbana de 1818 producto del reparto de solares, chacras y estancias estableció un primer ordenamiento espacial. El paisaje modificado quedó sujeto a la traza fundacional que dio origen al pueblo quilmeño. A través de un accionar meditado se buscó las ventajas del terreno para emplazar el pueblo y facilitar su vida de relación. En ese reparto quedaron establecidos los sitios para la Plaza Mayor (hoy Plaza San Martín), la Cuadra para las casas de los Capitulares y Cárcel, la cuadra para la Iglesia -habitaciones de los Curas- y las Plazas de la Caridad (hoy Plaza Falcón), de los Labradores (hoy Plaza Wilde), y del Regocijo (ex Mercado Municipal).

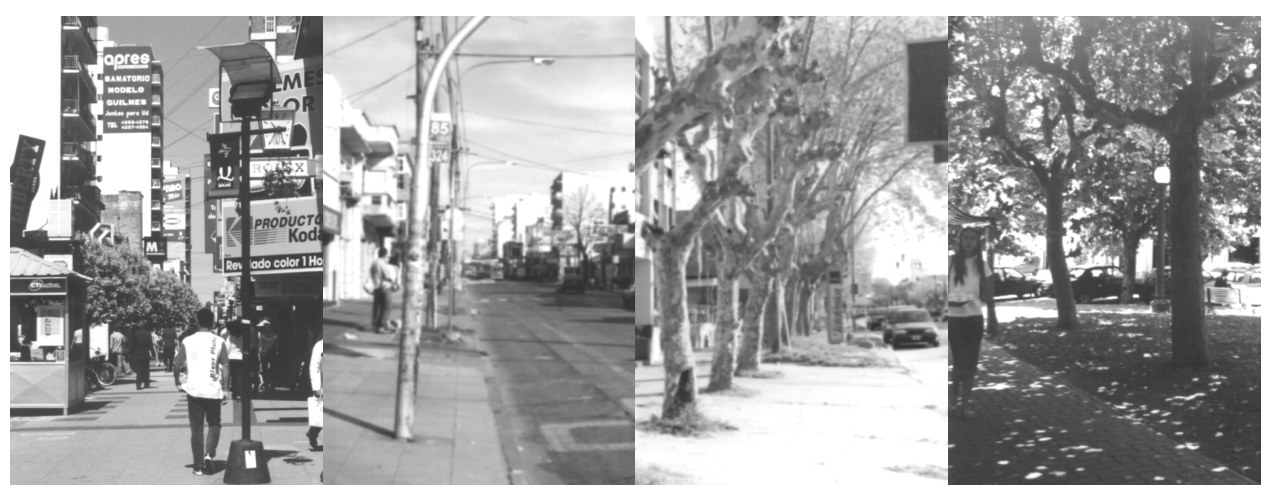

Figura 1 Imágenes de la delimitación del área de estudio de izq. a der. Peatonal Rivadavia, Avenida Yrigoyen, calle Alberdi y calle Sarmiento.

Fuente: CAMPARI (2001)

La valorización del área fundacional estuvo dada cuando se dio comienzo a la apertura de calles y a la construcción de edificios públicos que sirvieron de marco estructural para la inserción de las crecientes funciones políticas y administrativas del Estado?.

En la época en que el Partido de Quilmes todavía no había adoptado su fisonomía característica, en la zona ya se emplazaban casa-quintas, ranchos y algunas casillas que hasta las más humildes viviendas disponían de cierto terreno cultivado. Según las descripciones realizadas por (CRAVIOTTO, 1966:39) con respecto a la vegetación que se encontraba sobre el relieve topográfico de la zona, los sauces criollos y llorones, alisos, sarandíes negros y suiñandí, cortaderas y juncales se disponían en los grandes bajos. En las barrancas matorrales de calafate, ñapindá, flor de seda y mata ojo. En la planicie espinillo, porotillo, acacia, sombra de toro, brucuyá, zarza mora y tasi entre otras. En las partes más altas pequeños montes de talas, espinillos, algarrobos y chañares. Grandes montes de durazneros se medían por extensiones los cuales suministraban fruta y leña.

De calles de tierra apisonada con cercos vivos o construidos y terrenos baldíos que se encontraban en el centro del pueblo utilizados como potreros para los animales "Quilmes era el lugar preferido de veraneo para las familias aristocráticas porteñas, las cuales tenían casas con cochera, caballeriza, jardín, árboles frutales entre aromos de espinillo y magnolias" (TRAVERSI, 1949:12).

Los terrenos conformados delimitaron su área a través de cercos construidos; estos elementos lineales sirvieron de borde (LYNCH, 1998:62) para establecer una ruptura entre el espacio público y privado. La presencia de la vegetación tuvo protagonismo en el interior de los terrenos cultivados, con árboles de sombra o frutales como lo fueron los ejemplares de ombú, eucaliptos, araucaria, castaño, ciprés, tala, o materializando una división parcelaria dispuestos en grupos 0 alineaciones como ser de higueras, casuarinas, paraísos, sauces y acacias según el Plano Topográfico de 1890 (ALES, 1963).

\footnotetext{
2 Se construyó la primera municipalidad electiva (1856), inauguración del edificio municipal frente a la plaza principal (1860), instalación del alumbrado público con faroles a vela (1862), inauguración de la Esc. № 1 (1863), autorización para establecer el servicio de una diligencia (1868), instalación de 100 faroles a querosene, llegada del $1^{\circ}$ tren (1872), designación de las calles por orden numérico, inauguración del tranvía y de la Biblioteca Popular (1873), apertura de calles 8 (Videla) y 7 (Pringles) (1877), instalación del Telégrafo Nacional (1878), $1^{\circ}$ comisaría (1881), nominación de las calles de la planta urbana, establecimiento de la comunicación telefónica entre Quilmes y Bernal (1883), resolución para la construcción de la cloaca subterránea dentro de la traza urbana del pueblo por pozos en las esquinas (1884), establecimiento de la comunicación telefónica con Capital Federal (1885), creación de la $1^{\circ}$ cuadrilla municipal (1886). (ALES, 1968)
} 


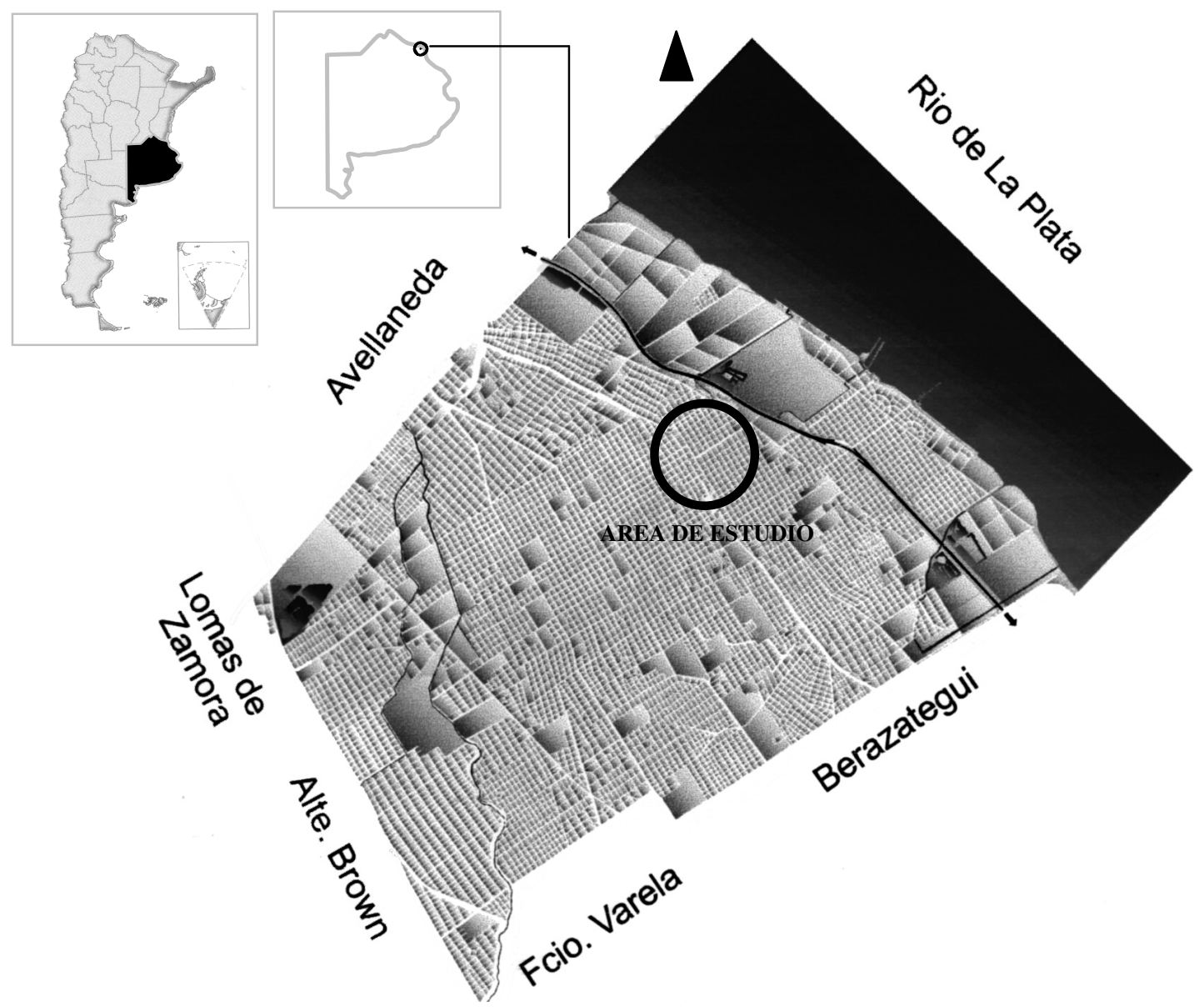

Figura 2 Inserción del Partido de Quilmes en la Provincia de Buenos Aires y sus límites. Fuente: Dirección de Estudios del Territorio (1997)

En torno a la plaza principal se fue ordenando el paisaje con la apertura de calles que organizaron el espacio para ser ocupado a través de los edificios institucionales: la iglesia, la municipalidad, la escuela y la comisaría. La plaza principal como un lugar de identidad, relacional e histórico (AUGE, 1996:84) ceremonial, festivo y de paseo fue el lugar cercano a las transformaciones, al comercio, al transporte y a los acontecimientos del pueblo. La plaza principal la cual dejó de ser un baldío cubierto de cicuta en primavera, (CRAVIOTTO, 1966:227) se consolidó como espacio verde a través de la jardinería pública. Impulsada por razones de higiene y ordenamiento, la plaza experimentó los primeros lineamientos compositivos de ornato en 1887 mediante la alineación de copudos paraísos en sus flancos y por caminos en diagonal cuyo recorrido estaba acompañado con árboles de sombra en ambos costados y un añoso pino centrado en cada ángulo (TRAVERSI, 1949:97).

En 1888 se crearon, en el pueblo quilmeño, las Comisiones
Vecinales en las cuales recayó la inspección sobre la higiene domiciliaria y de los establecimientos públicos. Estas vigilaron el cumplimiento de las Ordenanzas Municipales, funciones que se incorporaron con obligatoriedad al rol del Estado. Este urbanismo higienista estatal recibía diversas medidas tendientes al mejoramiento de la localidad en lo referido a la venta de pan, carne y leche como también sobre la existencia de los árboles y plantas en las calles y caminos. Por ese entonces se estableció la ordenanza sobre el tipo de cercos que se debían emplear para cercar los terrenos. Se hizo extensiva para todos los propietarios o encargados de las fincas o terrenos que se encontraban dentro de la traza del pueblo, la cual obligaba a cercar el frente de la propiedad lindante con la vía pública. Para el caso de las calles cercanas a la plaza principal la separación se debía materializar con edificios, paredes de ladrillo o verjas de hierro, en cambio para los terrenos más alejados de la traza fundacional y las restantes quintas sobre la barranca, la opción era más económica por lo que respondía a verjas de madera o tejido de alambre. La 
prohibición quedó establecida para la plantación de cercos o plantas sobre la línea municipal que invadiesen la vereda estorbando el tránsito. Por consiguiente los cercos vivos existentes debían ser arrancados para construir en su lugar aquellos que se habían establecido. Cabe mencionar que la misma ordenanza contempló la siguiente medida: "Se podrán poner árboles de sombra o plantas de adorno en el cordón de la vereda con previo aviso de la Intendencia (...)" (BUENOS AIRES, 1888). Esta medida sería ajustada años posteriores debido a los inconvenientes causados en su aplicación.

En el año 1894 por ordenanza (BUENOS AIRES, 1898) se dispuso la plantación de especies arbóreas de plátanos y/o paraísos al borde de las veredas a una distancia de 5 metros entre sí. A su vez se estableció la alternativa de que los vecinos en todas las demás calles pudiesen plantar las mismas especies, siempre en cuanto quedase respetada la distancia establecida por ordenanza.

En 1904 se establecieron una serie de capítulos que reglamentaron la plantación de los árboles en las calles de la planta urbana, con respecto a la distancia de plantación de árboles y a las autorizaciones respectivas. "La ciudad de Quilmes a pesar de su excelencia de su suelo, carece de una falta absoluta de plantaciones, reuniendo (...) los medios suficientes para hacerla en vasta escala.(...) Con la poda de los plátanos de las plazas y de los álamos y sauces de la rivera, se tendría una base valiosa para la formación de un vivero, cuya necesidad imprescindible se palpa día a día" (BUENOS AIRES, 1917/18:126).

La Intendencia tenía el poder de rechazar el permiso de los árboles que pudiesen alcanzar un desarrollo desmedido y antiestético, como también acordar la obligación de conservar los árboles podados con una altura inferior a los 5 metros. Con respecto a los cuidados, se estableció la prohibición de arrancar ramas de las plazas y caminos como también todo accionar que destruya el árbol o sus aparatos protectores.

La Ordenanza N 114 de marzo de 1921 hizo obligatoria la plantación de árboles en todas las calles y avenidas de la planta urbana de Quilmes en aquellas veredas que tuviesen 2,50 o más metros de ancho. Por primera vez las plantaciones quedaron a cargo de la Intendencia, siendo el cuidado, riego y la reposición de ejemplares en caso de pérdida por negligencia a cuenta de los vecinos. La misma exceptuó la plantación en las veredas que conformaban la trama céntrica, donde los árboles podían resultar un obstáculo para el intenso tráfico. Plátanos, tipas, robles y otros similares de hojas caducas eran los permitidos para la plantación, destacándose la importancia de guardar cierta uniformidad en las calles para lo cual resultaba más conveniente emplear una sola especie. "La comuna desea cumplir en forma intensiva una de sus obligaciones de índole urbanística, cual es la de aumentar la forestación de los centros poblados con el objeto de que de ello se deriven los beneficios sociales que importan las plantaciones arbóreas en las ciudades máxime en las que como la nuestra, día a día sufren mayores recargos en su atmósfera para la multiplicación de las actividades industriales. Cubiertas las necesidades higiénicas de referencia surjen las de índole estético y luego las de orden económico, todas indivisibles en la administración urbana. Superar esas necesidades hace a la función del gobierno comunal y por ello se pone en ejecución este vasto plan, que no lo dudo contará con el fervoroso apoyo de toda la población. Pero no solo en eso descansa la implantación de la Semana del Arbol. Existe otro (...) que se refiere al aspecto moral de la presencia del árbol en las ciudades (...) Quiere la Municipalidad inculcar en el cerebro y en el corazón de cada niño un verdadero amor al árbol, que no nazca sólo de la declamación laudatoria sino de la efectiva intervención en su cuidado, precediendo a su colocación y observando sus maravilloso crecimiento y sus magníficos frutos (...) que derive de la sabia enseñanza que a partir de hoy se procura brindar a nuestros niños" (BUENOS AIRES, 1946:48).

Los amplios terrenos con quintas y jardines se fueron delimitando por el fraccionamiento menor de las parcelas. La vegetación se fue acotando a espacios más reducidos en el caso de que estuviese presente, mientras que los árboles fueron dispuestos en el espacio público de la vereda, sostenidos a través de ordenanzas que determinaron la plantación de los mismos en la trama urbana. "Preocupación constante de esta Dirección ha sido y sigue siendo, el arbolado de las calles y paseos públicos. El árbol como valor ornamental o elemento moderador de la luminosidad estival, desde el punto de vista urbanístico pasa a ser en nuestro medio (...) un factor social de suma importancia (...) se ha procedido a la plantación de 2.000 árboles. Ello en procura también del saneamiento del aire viciado de nuestra populosa ciudad fabril. (...) Otro de los propósitos perseguidos por esta Dirección es crear en nuestro medio una conciencia de amor al árbol (...) con motivo de celebrar el Día del Arbol, se procedió a realizar un importante acto en la Escuela Provincial $N^{\circ} 14$ de Ezpeleta" (BUENOS AIRES, 1953).

En 1971 se declaró de interés comunitario la construcción y/o conservación de cercas y aceras de todos los inmuebles con frente a la vía pública de acuerdo con las Normas de Ordenamiento Urbano para la Zonificación Preventiva del Partido de Quilmes. En las especificaciones para la reparación y/o 
construcción de aceras la inserción de los árboles de alineación tuvo una escueta mención en el Decreto $N^{\circ} 10.444$ "Los cordones de cerramiento o remate de aceras y en huecos para árboles" (BUENOS AIRES, 1971:25).

El paisaje urbano condicionado por el tráfico y la verticalidad de lo construido, también se vio sujeto al cambio de rumbo de las acciones concernientes al arbolado de alineación. La crisis económica, la tercerización de trabajos operativos, el déficit de propuestas viables de arbolado, la adultez de algunos ejemplares arbóreos, la producción reducida de los viveros municipales, el sostenimiento de normativas aisladas y la falta de planificación construyeron el contexto en el cual hoy el arbolado público de alineación se encuentra inserto. Así fue como la tierra apisonada de las calles constituyó en una primera época un recurso natural (DOLLFUS, 1990:39) para hacer efectiva la circulación. Los trabajos de adoquinado que llegaron con posterioridad al igual que la construcción de veredas que reordenaron las vías de tránsito peatonal, se le sumaron los adelantos del alumbrado eléctrico público ubicado en el centro de las bocacalles y las alternativas de transporte como lo fue el tranvía.

La acción del hombre hizo que el paisaje no se creara de una sola vez (SANTOS, 1996:64), así las lámparas de tipo incandescentes sustituyeron a las anteriores, el pavimento reemplazó al adoquinado y el aumento del tránsito vehicular sustituyó a las vías del tranvía, mientras que la edificación en alto ha dejado obsoleta la relación de escala que existía con las primeras construcciones del pueblo.

El paisaje conformó un conjunto de formas heterogéneas en donde distintas épocas y elementos quedaron subordinados a un movimiento global (SANTOS, 1996:64). La calle principal, la de las quintas se transformó en la calle peatonal más comercial del Partido, saturada de publicidad, entre edificaciones antiguas y marquesinas modernas, constituye uno de los elementos más representativos de la imagen de la ciudad de Quilmes la cual refleja la complejidad del paisaje urbano.

El desarrollo de la sociedad y las complejas modalidades que acompañan a esta aglomeración urbana, han reflejado en el trazado de redes la densidad de la población. La red como construcción de una infraestructura para canalizar flujos, a través de un ordenamiento lineal y continuo ha permitido la interrelación con los distintos puntos habitados (DOLLFUS, 1978:73). Cuanto más compleja es la vida de los actores sociales que accionan sobre el espacio, mayor es el número de funciones y usos diversos que se interrelacionan y es de esta manera como el paisaje resulta heterogéneo (SANTOS, 1996:62). "La gente cree que el árbol que plantó en la vereda le pertenece, y no es así. La ordenanza 8114 deja bien en claro que el arbolado urbano le pertenece a la Comuna. Lamentablemente esta norma no está reglamentada lo que no permite un buen contralor de lo que ocurre con este arbolado. (...) Creemos que es una batalla perdida, sin embargo podemos concienciar para que la poda esté bien hecha ( ...) Este es un tema cultural, que entendemos sólo se puede combatir con educación, y por eso estamos programando una campaña de concientización (...) luchar por el problema grave, que es el desconocimiento de la gente de tratar el árbol que está en la puerta de su casa, que es la única reserva forestal que tiene la ciudad" (PERSPECTIVA SUR, 18/1/00:5-6).

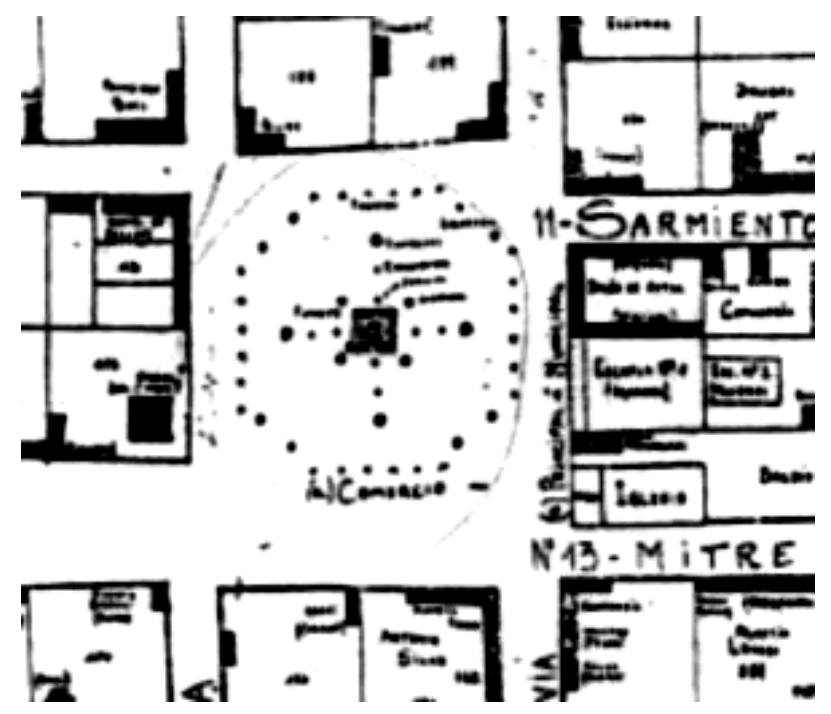

Figura 3 Plano de la distribución de los árboles de alineación en la plaza principal. Fuente: (ALES, 1963).

\section{Delimitación del área de estudio}

El área quedó sujeta a la trama ortogonal conformada por 42 manzanas las cuales abarcan una zona comercial y otra residencial, según la reglamentación de los usos, ocupación del suelo y parcelamiento de la tierra en el Partido. Por consiguiente el polígono de estudio quedó conformado por las calles y/o avenidas caracterizadas a continuación:

1- Calle Alberdi: como límite norte, zona residencial de casas bajas de principios de siglo XX y recientes construcciones en alto que fueron transformando el tejido urbano. Alberdi presenta la particularidad de ser una vía de circulación primaria, de tránsito mediano con doble dirección y llegada directa desde la avenida Yrigoyen a las dependencias de la nueva Municipalidad. De ceras muy anchas (más de 5 metros de ancho), las cuales en ciertos tramos ofrece diferencias de altura con respecto al nivel de la 


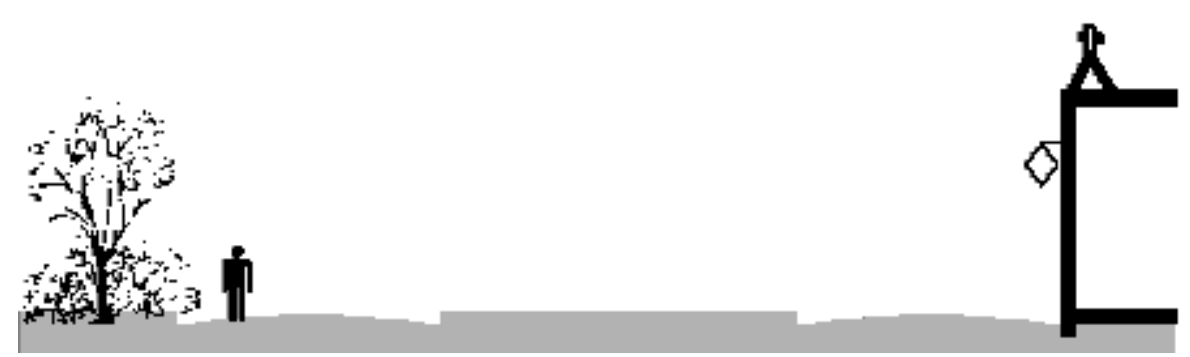

Corte 1: Centro vista de la plaza principal, izq. propiedad privada con vegetación, der. iglesia. 1862 alumbrado núblicn a vela

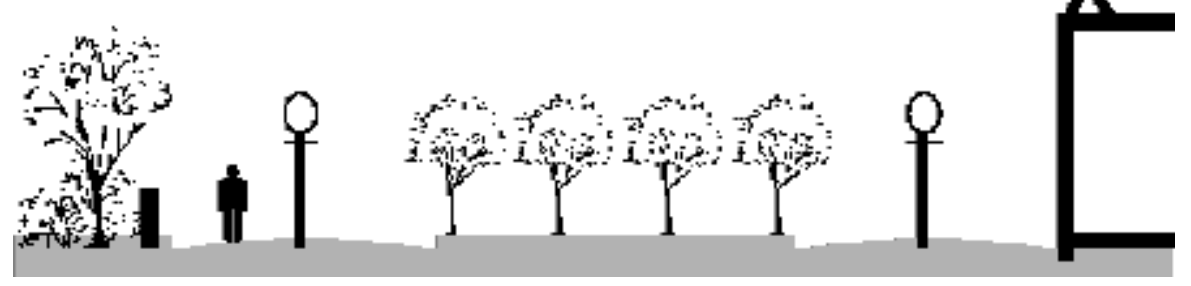

Corte 2: Centro vista de la plaza principal con arbolado de alineación, izq. propiedad privada con cerco construido. 1898 alumbrado público a electricidad mediante focos colocados sobre postes en las boca calles.

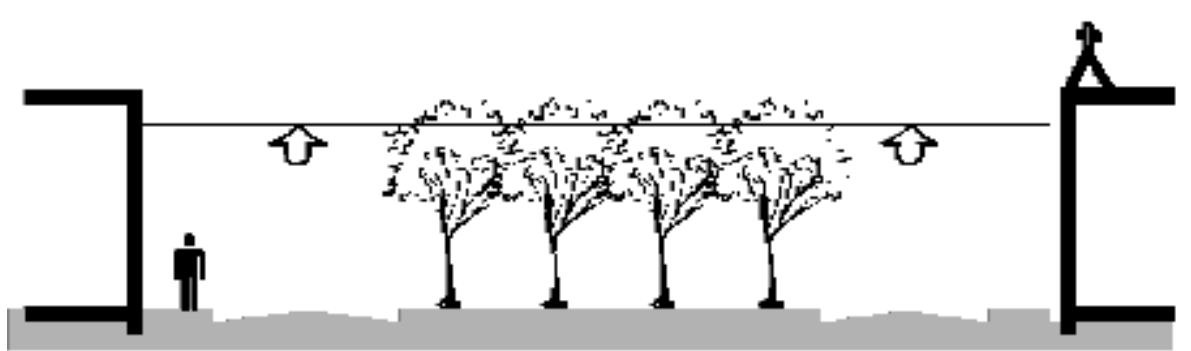

Corte 3: Tendido eléctrico de alumbrado público s/fecha.

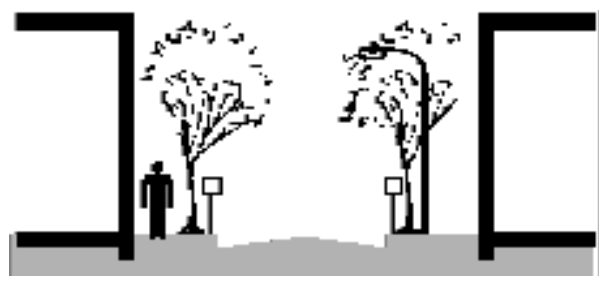

Corte 4: Vista calle lateral con luminarias y recipientes para residuos colocados en la vía pública.

Figura 4 Esquemas cronológicos de la aparición de la vegetación, servicios y mobiliario en la trama urbana.

Fuente: CAMPARI (2001)

calle y una franja destinada a una cubierta vegetal, que varía según la intervención de los frentistas. Esta calle mantiene una particularidad dado que ha mantenido por tramos las alineaciones de plátano (Platanus acerifolia) que correspondieron a las plantaciones originales realizadas por el Municipio.

2- Peatonal Rivadavia: como límite sur, en contraposición a la anterior se extiende sobre una zona comercial la cual tuvo referencias históricas significativas en la traza fundacional del pueblo quilmeño. La calle de las "Quintas" como lo era en la primera época fue dejando atrás sus características residenciales por las comerciales de moda. Rodeada de alta movilidad vehicular en sentido transversal, Rivadavia tuvo la particularidad de haber sido peatonalizada, nivelada y acondicionada para el tránsito peatonal intensivo como una alternativa de paseo y de reunión. 
Contenidos en canteros elevados se encuentran las plantaciones de ligustro variegado (Ligustrum lucidum for. aureo-marginatum) que refuerzan la partición del espacio peatonal a través de la alineación.

3- Calle Sarmiento: como límite este se extiende sobre un sector que corresponde a las inmediaciones de los antiguos edificios cívicos y de la plaza mayor la cual conserva la alineación de plátano (Platanus acerifolia) como envolvente. Heterogéneo en cuanto a las características de las construcciones de su entorno, Sarmiento se caracteriza por ser una vía secundaria inmersa en la zona comercial anteriormente mencionada. El otro tramo se encuentra en zona residencial en el cual los nuevos emprendimientos edilicios han transformado su fisonomía a través de las alternativas en el tratamiento de fachadas, de veredas, en las nuevas entradas vehiculares y en los accionares reflejados con respecto al arbolado urbano.

4- Avenida Yrigoyen: el límite oeste se encuentra dado por esta gran vía de circulación primaria, de doble dirección, con un tránsito vehicular intenso y una circulación diaria de personas que se trasladan a través de los servicios de transporte de colectivos y ferroviario. Por tramos de tipo comercial y por otros librados al abandono, sobre esta concurrida avenida tienen lugar dos de las famosas cadenas de supermercados y la redacción del periódico local. Si bien el ancho de vereda sería el conveniente (más de 4 metros de ancho) para realizar cualquier tipo de plantación, y dadas las condiciones reinantes del tránsito vehicular, la presencia de la vegetación para este caso es casi nula.

\section{Metodología de investigación}

Para la elaboración de este trabajo se ha recurrido primeramente a la búsqueda de diversas fuentes de información, escritos oficiales (registros del Municipio, memorias municipales, documentación jurídica y legal de las intervenciones urbanas), estadísticas, documentos cartográficos del sitio como así también material fotográfico y periodístico de época.

Con el objeto de obtener datos cuali y cuantitativos se llevó a cabo un relevamiento de los ejemplares. El tamaño de la muestra quedó determinado por las 42 manzanas que conformaban el área de estudio.

A través de una planilla técnica se relevaron todos los árboles, arbustos y/o palmeras existentes en las veredas de calles y avenidas, como también aquellos sitios potenciales cuyo signo estaba dado por las planteras construidas que carecian de árbol y/o ejemplar alguno. La planilla se componía de campos a relevar que hacian referencia a la dirección, especie, circunferencia, altura, ancho de vereda, estado seco y datos concernientes al maltrato y a las interferencias, información que requería un mayor análisis dada la hipótesis planteada.

A su vez metodológicamente se trabajó en el marco de la escuela geográfica de la percepción, la cual toma al paisaje haciendo hincapié en el interés por los vínculos y el peso que arrojan las subjetividades sociales al interactuar y construir el espacio social. "Actualmente para la valoración del paisaje en los planes territoriales, además de evaluar factores como la cobertura vegetal, la pendiente (...) suele tenerse en cuenta la opinión de los usuarios potenciales (...) expresable mediante encuestas u otros sistemas de investigación social que ayudan a descifrar las preferencias subjetivas del público" (CAPEL, 1982:45). Es la historia oral, los elementos significativos y las reacciones ante el problema, lo que dejan traslucir las formas de ver el paisaje. "Todo lo que vemos, o que nuestra visión alcanza es el paisaje. Este puede definirse como el dominio de lo visible, lo que la vista abarca. No sólo está formado por volúmenes, sino también por colores, movimientos, olores, sonidos, etc. (...) Por tanto el paisaje como el espacio resultan de movimientos superficiales y de fondo de la sociedad, de una realidad de funcionamiento unitaria, de un mosaico de relaciones, de formas, de funciones y sentidos" (SANTOS, 1996:59).

Para tal caso se recurrió a la elaboración de 8 entrevistas a actores sociales claves en base a interviews (DUVERGER, 1996:286) técnica que permitió obtener un disparador de respuestas más libres, por la ductilidad y la adaptación de la misma. Las preguntas se orientaron a indagar acerca del conocimiento del árbol del frente de su casa (cuidados, sombra, molestias), si colaborarían en caso de recibir asesoramiento, apreciaciones sobre las tareas realizadas por la Municipalidad, opinión con respecto a los problemas y beneficios de los árboles urbanos.

Cabe destacar en esta instancia que dada la complejidad y las dificultades surgidas por los términos establecidos de tiempo, se ha dejado abierta la continuidad de las indagaciones a efectos de que futuros estudios puedan llevarse a cabo, si se cuenta con los medios y recursos necesarios para su accionar.

En una tercera instancia metodológica se implementó la fotografía como herramienta testimonial, para materializar observaciones directas de la interacción de actores sociales y su contexto. Se realizaron diferentes tomas fotográficas del área de estudio, dirigidas a registrar las diversas conductas adoptadas con respeto a la presencia 0 no del árbol y las consecuencias negativas derivadas de un tratamiento incorrecto. 


\section{Resultados}

Se relevó una cantidad total de 1132 ejemplares pudiéndose establecer la existencia de $27(26,95)$ ejemplares/ manzana es decir unos $7 /$ cuadra, siendo un $42 \%$ árboles adultos de 1 a 1,60 metros de diámetro. El total de especies relevadas sumó 63 , siendo las especies predominantes el fresno americano (Fraxinus americana) con 304 ejemplares y el plátano (Platanus acerifolia) con 170 . El $71,42 \%$ son árboles, el $20,63 \%$ son arbustos y el 6,34\% son palmeras entre las cuales la pindó (Arecastrum romanzoffianum) contabilizó una cantidad de 13 ejemplares. Tanto el fresno americano (Fraxinus americana), plátano (Platanus acerifolia), sófora (Sophora japonica), tilo (Tilia sp.), crespón (Lagerstroemia indica) mantuvieron el carácter de especies predominantes al comparar éstos con los resultados obtenidos en los trabajos de campo realizados en el Municipio (ADOQUE, 1998), disponibles en la Dirección de Estudios del Territorio de la Municipalidad de Quilmes, a excepción del acer (Acer negundo) que de estar en un $7^{\circ}$ lugar pasó a ubicarse estadísticamente tres lugares inferiores. Si bien el plátano (Platanus acerifolia) representa la $2^{\circ}$ especie predominante, registró una baja en la cantidad de árboles comparativamente al relevamiento realizado por Adoque. En relación a la diversidad es decir al número de especies aumentó de 56 a 63 . En general todas las especies sufrieron un aumento en cuanto a su cantidad, pero en especial la diferencia fue considerable para el ligustro variegado (Ligustrum lucidum for. aureo-marginatum) que aumentó un $133 \%$. Por el contrario sucedió con el acer (Acer negundo) el cual de 25 individuos pasó a tener 23. La diferencia a favor que da el muestreo realizado con respecto a la cantidad total de ejemplares pudo estar fundada por diversos motivos, uno de ellos es que haya aumentado la plantación de árboles en las veredas, lo cual sería positivo a escala local, o simplemente porque existió un error de conteo en los trabajos anteriores.

Otros resultados registrados respondieron a 13 árboles secos (1\%), 46 árboles faltantes (4\%), un 6,65\% presentó un descope parcial. De los 261 árboles/arbustos jóvenes 58 solo estaban tutorados $(22,22 \%)$.

Un 5\% de los ejemplares relevados presenta algún tipo de agresión antrópica por causa de elementos externos al árbol que condicionan el normal crecimiento del individuo. Un $36 \%$ correspondió a las amarras (A), un $22 \%$ a los cestos de basura (B), $12 \%$ a carteles (C), $9 \%$ escrituras o gravados en cortezas (E), mientras que un $2 \%$ a cestos y carteles conjuntamente $(B / C)$. Entre el $12 \%$ que agrupa a diversos tipos de agresión se encontraron casos de elementos punzantes clavados, maderas clavadas, troncos pintados, elementos de relleno en huecos de la corteza entre otros.

Un 39\% sufre algún tipo de interferencia. El 18\% correspondió al cableado aéreo de empresas de servicio (C), 18\% a la presencia de todo tipo de postes en uso o en desuso (P). Con un $4 \%$ se reunieron aquellos tipos de interferencias diversos que se han encontrado como ser marquesinas, balcones, tensores, toldos, pilares (O). Un $2 \%$ reunió a los casos en los cuales los cestos de basura condicionaban el desarrollo del ejemplar (B) y con un $1 \%$ a los carteles sean éstos de señalización, de propaganda, etc. (CA).

A partir de los resultados de las entrevistas a testigos claves se pudieron definir claramente dos tipologías: una que reflejó una respuesta positiva frente a la existencia del individuo arbóreo y otra una actitud indiferente. Con el objeto de ejemplificar cada una se transcribieron los párrafos más significativos de las entrevistas a fin de no exceder la capacidad convenida para la exposición del presente trabajo. Las entrevistas no revelaron la identidad de los entrevistados con el objeto de preservar la privacidad de los mismos.

\section{Tipología A - Actitud positiva frente a la existencia del individuo arbóreo}

En los 6 casos consultados existió una coincidencia por tener un cierto conocimiento del árbol que tienen en su frente. Dos de los casos declararon haberlos plantado y en ambos se da la característica de ser un tipo de vivienda edificio ajardinado. En uno de ellos el portero se remontó a seis años atrás "Terminada la obra el árbol que había en la vereda estaba seco, la misma propietaria que hizo el jardín consiguió el árbol, primero le habian traído otro pero no era ese el que quería para el edificio, así que éste era el que buscaba" señalando el liquidambar (Liquidambar stiracyflua). El otro edificio prestaba servicios un paisajista realizando las tareas de diseño y mantenimiento, dada mi sorpresa al encontrar una serie de lapachos (Tabebuia sp.) plantados en la vereda me comentó "Nos guiamos por el lapacho que se encuentra en la otra cuadra el cual merece su admiración, pero cuesta mantenerlos y el crecimiento está siendo muy lento". El resto sabía cual era la especie si se estaban refiriendo al tilo (Tilia sp.), plátano (Platanus acerifolia) o fresno americano (Fraxinus americana). Fue en un solo caso en los cuales los propietarios se acercaron mientras estaba realizando unas mediciones y entablaron ellos mismos la charla. "Es muy limpio, la hoja es parecida al del vecino pero no florece igual, entonces es una acacia?". 
El tema del cuidado se hizo extensivo en casi todos menos en un comerciante de artículos varios de bazar que respondió "no porque así solo está bien".

El disfrute de la sombra estuvo presente en las tres casas particulares de principios de siglo en las cuales los ejemplares eran adultos habiendo desarrollado buena copa, características idénticas se registraron en el comercio mencionado. Lo contrario se dio en los edificios donde los ejemplares todavía tenían muy poco desarrollo.

Las preguntas negativas acerca de si el árbol le molesta 0 si lo sacaría no prestaron conformidad. "En esta cuadra había más tilos pero lo fueron eliminando con kerosene, entonces la Municipalidad al verlos secos los fue retirando y después plantan otra cosa, señalando el ficus (Ficus benjamina) del negocio de al lado. El tilo no me estorba la vidriera, me da beneficios que hace que lo valore aún más. El comerciante hace lo que quiere con los árboles".

"En la cuadra había muchos árboles, pero vos te das cuenta los que hay, y no solo eso, este fresno debe hacer más de setenta años que está plantado acá. Cuando vine a vivir ya estaba, en cambio si te fijas los pocos que quedan son muy nuevos, porque los reemplazan rápidamente".

Sí mostraron una actitud positiva con respecto a la posibilidad de colaborar si los asesoraran. "Lo riego todos los días en verano, es por eso que el follaje tiene un verde más intenso" (...) "Doné 200 plantines de fresno a la Municipalidad y por suerte los destinaron a una zona de viviendas".

En relación a las tareas que realiza la Municipalidad varias fueron las críticas de cierta ineficiencia ante la realidad. "La Municipalidad no controla".

"El supermercado (...) construyó un sector para descarga de camiones, pero como los camiones tienen que hacer cola de espera, los tengo parando en el frente de mi casa (la casa se encuentra a una cuadra). A raíz de eso un día dieron marcha atrás y partieron este plátano enorme. Me dio mucha pena y tenía miedo de que se secara, entonces lo atravesé con dos pernos para que pueda recuperarse y se recuperó. El otro tiene estos huecos que son muy grandes, los estoy rellenando con un material que sale muy caro. Estos trabajos los tendría que hacer la Municipalidad pero...".

"Las empresas constructoras hacen casa nueva, vereda nueva y árbol nuevo. En la esquina había árboles más grandes, los sacaron, por lo menos la arquitecta tuvo la decencia de plantar dos más".
Cuando se hizo mención de los problemas que traen aparejados los árboles en la ciudad la mayoría lo relacionó con el levantamiento y rotura de veredas. Uno sin embargo acotó: "El árbol no causa problemas, es como si vos a un hijo a los 30 años le pones un zapato de cuando tenía 9. Necesita su lugar para crecer y desarrollarse. La gente no respeta eso, el árbol es una vista más de lo que nos pasa a los argentinos".

En los beneficios vuelve a surgir la sombra que proyectan los árboles en verano y hubo dos menciones que lo relacionaron con la belleza y la oxigenación. $Y$ en cuanto a las preferencias nuevamente la sombra se llevó todos los elegios. "Disfrutamos en verano porque la sombra es muy densa".

\section{Tipología B - Actitud indiferente frente a la existencia del individuo arbóreo}

En 2 de los entrevistados el diálogo resultó mucho más forzado que el anterior. Los temas no fluyeron ni despertaron otros comentarios que pudieran hacer un aporte más significativo. En relación al conocimiento que se tenía por el árbol de su frente, uno de los casos una peluquera, cuyo negocio se encontraba en una de las transversales muy cerca de la peatonal no reparó en el árbol seco que lindaba con la parcela de al lado. "Estaba así cuando vine". "Me resultan indiferentes, no conozco nada, y sí molestan te tapan la vidriera".

Cuando se le pidió que por lo menos mencionara alguna preferencia para el arbolado de la ciudad dijo la sombra "Me gusta caminar debajo de la sombra en verano".

El segundo caso tenía la particularidad de ser un edificio de la década del '60, con vereda hecha a nueva pero sin árboles. Una de las propietarias argumentó que desde que vive ahí hace más de 30 años nunca hubo árboles plantados y la verdad que no sabe por qué. La oxigenación y la belleza las enumeró como dos de los beneficios de los árboles en la ciudad, mientras que la sombra volvió a aparecer como preferencia.

Debido a que en las entrevistas realizadas no se pudo rescatar una respuesta negativa ante la presencia de los árboles en las veredas, se determinó ejemplificar este tipo de actitud a través de la fotografía como herramienta testimonial. Para tal caso se las reunió en otra tipología en la cual primaron las actitudes ligadas a la liberación del miedo, del peligro, de orden y de manipulación por lo inmediato que rodea al vecino. 


\section{Tipología C - Actitud negativa frente a la existencia del individuo arbóreo}

Se detectaron 39 casos en los cuales el accionar humano dejó reflejar inconvenientes en los árboles insertos en la trama de la ciudad quilmeña. Las prácticas clandestinas sean podas drásticas, eliminación de ejemplares por entradas vehiculares, realce de fachadas, o nuevas construcciones hacen que el vecino adopte conductas de apropiación en ciertas decisiones concernientes al arbolado de alineación. Fue necesario dado el material que se fotografió establecer una clasificación, la cual permitió un ordenamiento de las realidades de acuerdo a las tipologías que se fueron presentando:

C1: Se detectaron 6 casos los cuales presentaron situaciones problemáticas con respecto a la falta de planificación en la cual quedó en evidencia la intervención no adecuada del vecino y las falencias en la previsión del arbolado. En los casos detectados se hicieron presentes situaciones relacionadas con espacios vacantes como ser estando la plantera vacía, es decir sin la existencia de un ejemplar, se dispuso en ese lugar el canasto de residuos domésticos dado que su implementación se vio favorecida por el hoyo de plantación existente; las plantaciones privadas de varias especies arbustivas que comparten una plantera como así también el caso de un ficus (Ficus benjamina) plantado en una maceta rota directamente en la plantera disponible de la vereda; la vereda a nueva en la cual se ha dejado de colocar un baldosón para materializar el hoyo de plantación sin la previsión necesaria a futuro por la suficiente disponibilidad de espacio; el cerramiento improvisado de la plantera a fin de salvaguardar las herbáceas plantadas al pie del ejemplar arbóreo como así también el caso del ejemplar arbóreo que ante el ensanchamiento de su tronco ha invadiendo el cordón por la no previsión de su crecimiento (Fig. 5).

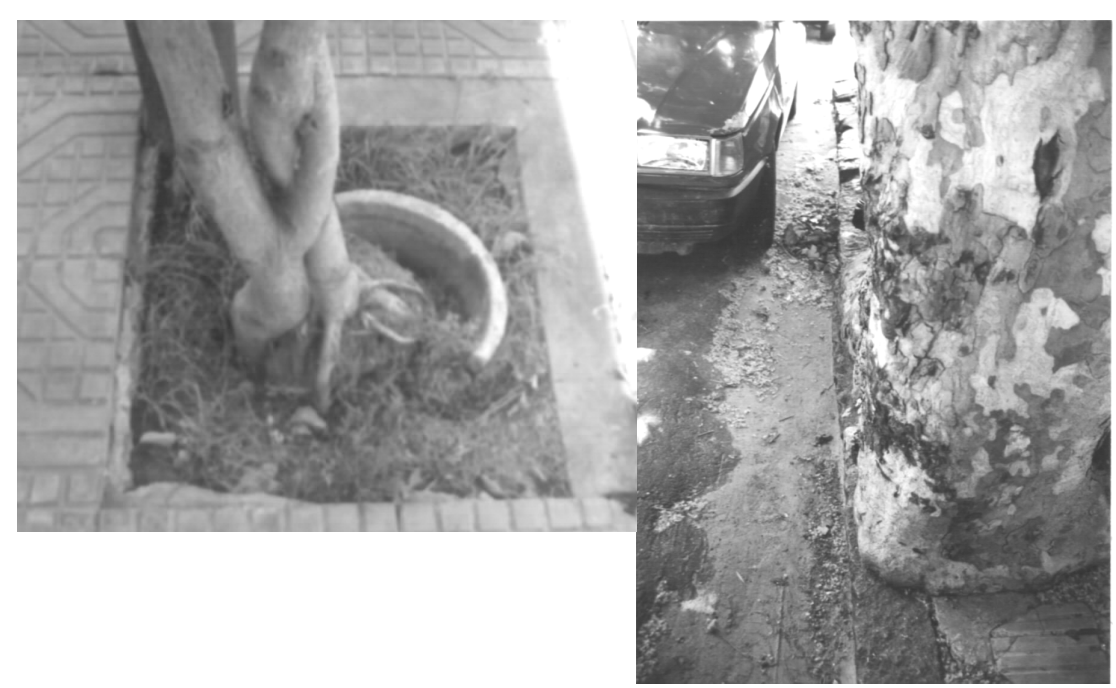

Figura 5 Imagen izq. Caso ficus (Ficus benjamina) plantado con maceta. Der. Caso plátano (Platanus acerifolia) que creció sobre el cordón de la vereda.

Fuente: CAMPARI (2001)

C2: En estos 4 casos se reflejaron situaciones en las cuales el árbol pasó a cumplir una función de sostén de elementos adicionados e impuestos como lo fue para el caso de carteles publicitarios amarrados o clavados en el tronco de los árboles 0 en las obras en construcción que necesitaron fijar parantes 0 extensiones para sujetar chapas perimetrales 0 andamios en los troncos como el medio más cercano y seguro por su no "movilidad" (Fig. 6).

C3: En 5 casos el accionar vecinal se encontró sujeto a la incorporación de materiales diversos como ser maderas, cemento, ramas, trapos para subsanar caseramente las cavidades en los troncos de los mismos que despiertan malestares, sensaciones de inseguridad o precaución en la gente. En estos casos tuvo lugar los inconvenientes causados por las podas, acortamiento de ramas 0 talas indiscriminadas practicadas por agentes no autorizados con el objeto de anticiparse ante la caída de las hojas en la estación invernal.

C4: Los 5 casos reunieron características en las cuales postes, luminarias y tensores comparten con el árbol tanto el espacio aéreo como el subterráneo. Si bien pueden existir situaciones más complejas en algunos casos que en otros, éstas resultaron ser repetitivas en todo el Municipio. 


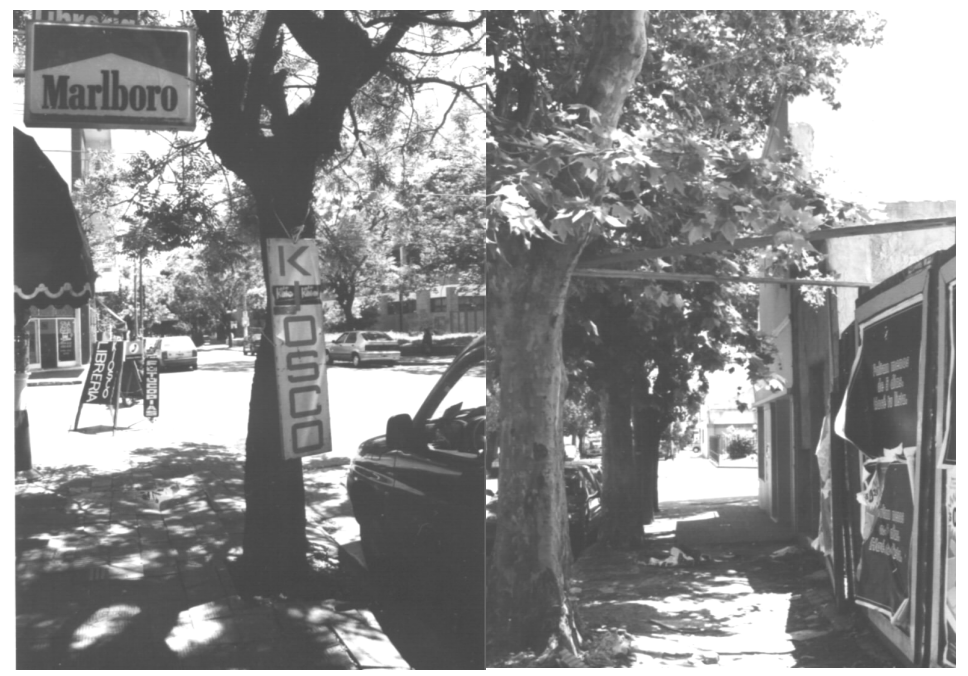

Figura 6 Imagen izq.Caso cartel publicitario clavado sobre tronco. Der. Caso plátanos (Platanus acerifolia) como sostén de andamios en obra.

Fuente: CAMPARI (2001)

C5: En 8 de los casos se vio reflejada la problemática de la deposición de los residuos domiciliarios en las calles de la ciudad. Lejos de la altura de los animales vagabundos, contenida en receptáculos especiales e individualizada según el frente y el uso, hizo que se necesite lugar para la ubicación del material residual producido diariamente. Los árboles resultaron ser en estos casos el soporte ideal para la colocación del canasto, el clavado de ganchos sujetadores, de cadenas para prevenir los robos del contenedor; como así también el contacto íntimo con estos recipientes hizo que el árbol siguiera creciendo incorporando materiales metálicos a su corteza (Fig. 7).

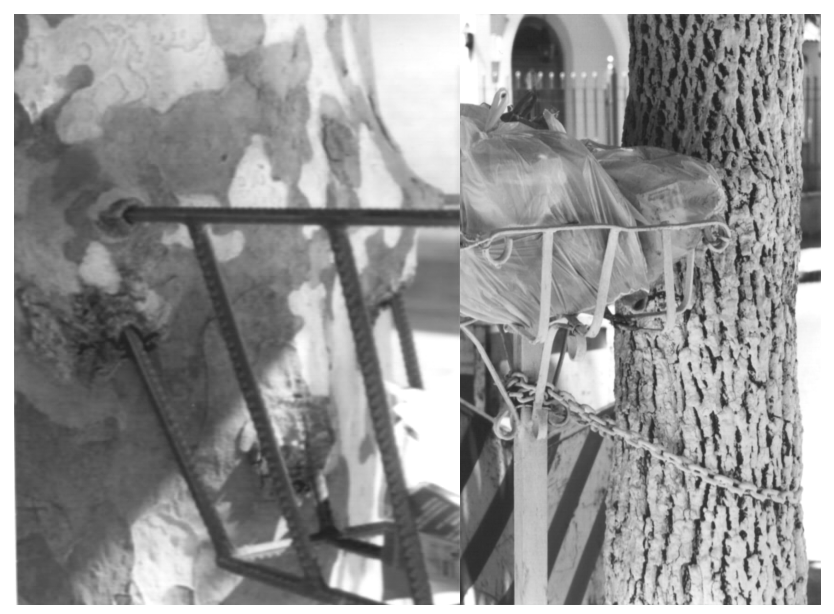

Figura 7 Imagen izq. Caso plátano (Platanus acerifolia) creció incorporando al cesto de residuos metálico. Der. Caso cesto pintado de blanco al igual que el tronco del árbol encadenado. Fuente: CAMPARI (2001)
C6: En 4 de los casos se encontraron problemáticas relacionadas con las amarras o sujetadores tales como el tutor de un árbol recién plantado sostenido con alambre de púa; una empresa de servicios que no vio mejor lugar que enrollar los sobrantes de un cableado aéreo al tronco de uno de los árboles o simplemente las amarras de nylon sujetas a lo alto de las ramas de un árbol indicios de un pasacalle que ha quedado en desuso (Fig. 8).

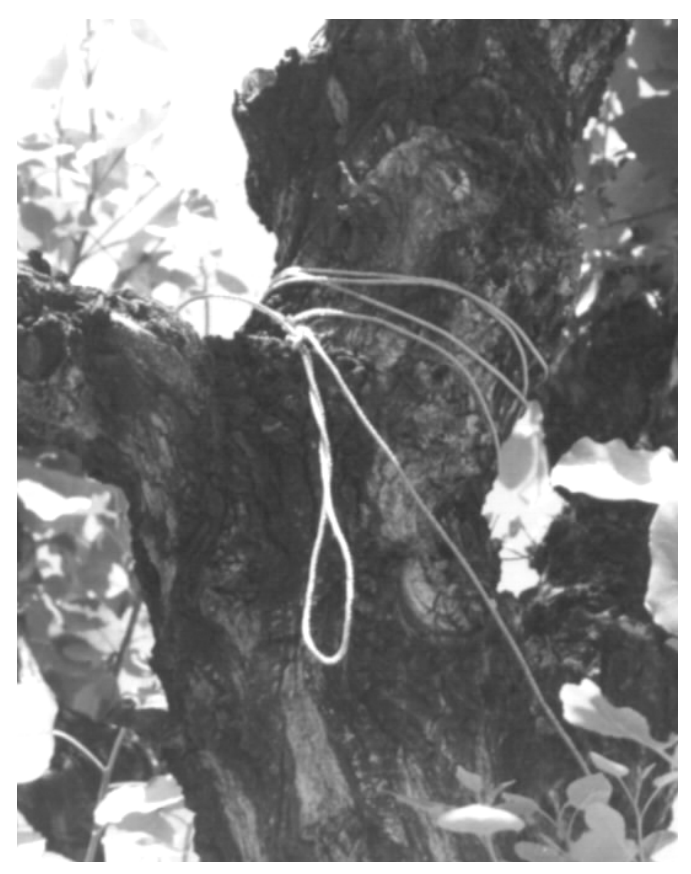

Figura 8 Imagen amarras obsoletas en el tronco. Fuente: CAMPARI (2001) 
C7: Fueron 7 los casos en los cuales las veredas en las cuales se ha cambiado el solado no se concibieron los espacios destinados para la plantación de árboles, avenidas sin vegetación, nuevas entradas vehiculares, ejemplares que han sido extraídos y tapadas sus planteras producto de nuevas construcciones edilicias en el Partido.

Luego de desarrollar los temas expuestos, resulta necesario recurrir a lo que se enunciara al comienzo del trabajo para afirmar que el factor antrópico es un agente de degradación del paisaje urbano cuya incidencia notable se percibe en el arbolado, constituyéndose éste en un indicador de perturbación paisajística negativa si no se establece una adecuada planificación de tareas con la finalidad de intentar despertar el interés por el cambio de ciertas actitudes humanas para revalorizar su valor en el paisaje urbano.

Cabe en esta instancia aclarar que el hombre se relaciona con la realidad a partir del vínculo que establece con las representaciones sociales. Estas representaciones dependerán de las formas y maneras de ver el mundo que cada individuo posee. Las distintas personas podrían reaccionar de forma diferente frente a los mismos estímulos ambientales condicionados por su propia subjetividad, por las tradiciones, motivaciones, por la historia del grupo de pertenencia o por su experiencia personal. Las mismas características físicas de ese entorno pueden desencadenar efectos diversos según los momentos, posición del observador, estado psicológico de éste y desigualdad de atención. Es por eso que las acciones individuales y sociales sobre la realidad social están condicionadas por la percepción 0 representaciones construidas. Por consiguiente cabe aclarar que este factor antrópico interviene en forma:

- Positiva cuando con su accionar beneficia la existencia de los árboles en las aceras de calles y avenidas como ser: lo que han reflejado las entrevistas a testigos claves los cuales afirman tener conocimiento sobre el ejemplar que tienen en el frente de su casa; cuando existe esa intención de realizar una nueva plantación y los cuidados pertinentes hacia el mantenimiento del ejemplar, aluden que colaborarían si lo asesoraran; cuando despierta el interés de los árboles porque reconocen el beneficio que provoca la sombra en verano o el colorido de la floración.

- Negativa cuando con su accionar perjudica y perturba su desarrollo como ser: lo reflejado en el relevamiento en el cual un $39 \%$ de los ejemplares arbóreos sufre algún tipo de interferencia para su normal desarrollo como lo son los cableados aéreos y los postes de servicios; los indicios de agresión a través de amarras, escrituras o presencia de elementos extraños o punzantes; la eliminación de los ejemplares de las veredas, las podas indiscrimi- nadas, la falta de previsión de los organismos competentes para evaluar el aumento de la diversidad de especies por una intervención vecinal y los árboles saltantes entre otros.

Pero esta intervención negativa puede tener bases en actitudes que responden a:

- Accionar directo no intencional es el caso de todo el mobiliario urbano presente en el espacio público, que convive con los árboles en uso o estando obsoleto, el cual por la falta de una planificación acorde se superpone en la vía pública. Pero también resulta una forma negativa de proceder cuando el frentista interviene de manera no ordenada atentando a cualquier posible planificación a implementar, o el Municipio no responde a término a las demandas referidas al arbolado por inconvenientes presupuestarios.

- Accionar directo e intencional es el caso en el cual existe un objetivo a cumplir a cualquier costo (me estorba la fachada, me molesta, lo saco o las empresas de servicios utilizan las aperturas de los hoyos donde se encuentran plantados los árboles para la colocación de los postes).

\section{Propuesta de ordenamiento mediante la intervención vecinal}

Según los resultados obtenidos, la diversidad resultó ser elevada a la cual se le adicionó, la intervención vecinal que ha interferido de forma contundente y sin planificaciones previas a lo largo de los años.

Pensar en derribar todo lo existente para establecer ciertos ordenamientos mínimos en el arbolado sería una actitud que escapa de toda posible intervención con metas a corto plazo. Cabe aclarar que se deben establecer dos ejes: uno orientado al mantenimiento y otro a la planificación propiamente dicha. Si bien este trabajo apunta al primer eje mencionado, en el momento de las decisiones la interacción de ambas partes resultaría fundamental debido a que comparten las problemáticas del arbolado de alineación desde diferentes miradas de la realidad. Todo plan no puede implementarse si no está avalado por las normas respectivas para su aplicación. Resulta de fundamental importancia rever las ordenanzas y decretos existentes con profesionales idóneos en el tema a fin de cumplimentar las condiciones más relevantes y adecuadas para la integración del árbol en la ciudad. Es por consiguiente que se deberán tomar los recaudos necesarios para conocer el patrimonio arbóreo del Partido con la máxima precisión, siendo necesario efectuar diversos estudios que continúen y enriquezcan las tareas que se dieron comienzo en este trabajo. 
En lo referido al mantenimiento y prevención la propuesta estará sujeta a la intervención vecinal como un instrumento alternativo para modificar actitudes antrópicas negativas percibidas en el arbolado, en favor del ejemplar como así también en la optimización de resultados que permitan consolidar la acción del Municipio. Intenta reunir aquellas problemáticas detectadas en el arbolado público en las cuales el vecino 0 las organizaciones competentes podrían intervenir de manera ordenada y asistida. Existen ciertos inconvenientes, como se los ha desarrollado oportunamente, desencadenados por maltratos, interferencias, tutorados, reclamos entre otros, para los cuales estos actores sociales pueden llegar a ser los más indicados para el seguimiento de todo programa a implementar. Si bien no están contempladas aquí aquellas acciones que requieren de una intervención técnica como lo es la poda o los controles sanitarios, pero sí aquellas acciones que puedan ser extendidas a todo aquel actor social sin discriminación de género 0 edad, que se encuentre comprometido con el cuidado de los árboles, la propuesta se sustentará en los siguientes ítems:

1) Fomentar la valorización del arbolado público a partir de la memoria colectiva del Partido de Quilmes; a través del "Sentido histórico", esto es, una actitud mental habituada a la dinámica social, apta para encarar el estudio de una realidad en su interrumpido proceso de transformación" (LOMBÁN, 1990:12); 2) conformar grupo/s de trabajo interdisciplinario/s; 3) fomentar la intervención vecinal organizada con asesoría directa de profesionales del Municipio; 4) establecer el compromiso entre profesionales y vecinos a fin de consensuar problemáticas del arbolado de alineación; 5) realizar un empadronamiento de aquellos actores sociales (líderes sociales, promotores voluntarios de la comunidad, escuelas y Organizaciones no Gubernamentales -ONG's-), que posean cierta vinculación con el tema para planificar programas de acción específicos; 6) convocar a los diferentes actores sociales estableciendo grados de participación; 7) originar una necesidad y un entusiasmo para que los participantes se sientan dueños de la idea (BOTINNI DE BARUCCA, 1990:3) y aporten soluciones a las problemáticas del arbolado público. Responsables del éxito o fracaso de la sociedad y viendo al Estado como su instrumento y colaborador y no como su obstáculo ni como su líder; 8) trabajar desde el conflicto y la contraposición de intereses en base al consenso; 9) definir cuestiones estratégicas y acciones tácticas referidas al arbolado; 10) instruir a supervisores voluntarios para el seguimiento de los proyectos; 11) formar multiplicadores de conductas que trascienda a otros ámbitos de acción.
Dentro de los diferentes niveles de la participación, se podrían considerar la participación de responsabilidad individual del ciudadano a escala vecinal, en lo que hace a los actos domésticos y diarios en mejora del árbol que tiene en el frente de su vivienda: 1) detección y eliminación de todo elemento externo que deteriore su normal crecimiento (cestos de residuos, objetos punzantes clavados, amarras, etc.); 2) seguimiento de los árboles adultos y jóvenes para asistirlos en caso de reemplazo, suministro de tutor y/o amarras, liberación de las amarras sujetadoras, plagas y enfermedades; 3) limpieza y/o mantenimiento de planteras, tepes y canteros; 4) supervisión voluntaria de acciones indebidas en el vecindario que involucren al arbolado de alineación; 5) divulgación de las tareas que se realicen a vecinos o personas de su conocimiento.

Como así también de responsabilidad colectiva y la participación en acciones del barrio organizadas a través de: 1) participación en reuniones con las dependencias públicas; 2) conformación de talleres en los cuales se instrumente una recorrida histórica del árbol en la ciudad a fin de despertar la conciencia hacia el correcto manejo; 3) organización de galerías fotográficas en las cuales se evidencie la problemática real del arbolado en el Partido con el objeto de movilizar al vecino a través de su propio ejemplo; 4) campañas educativas en instituciones públicas y privadas y la comunidad en general que fomenten la concepción del arbolado como patrimonio de la ciudad de Quilmes en sus dimensiones históricas, ambientales y paisajísticas; 5) confección de registros de reclamos sectorizado (de interferencia de cableado aéreo, interferencias en el espacio subterráneo, uso incorrecto del espacio público por parte de las empresas de servicios, levantamiento de veredas, etc.); 6) detección de ejemplares para ser utilizados como árboles semilleros en los viveros municipales y para establecer un seguimiento fenológico de los mismos; 7) supervisión y control de las operaciones tercerizadas en lo que respecta a la forestación, extracción como también otras tareas operativas en las cuales el arbolado se encuentre afectado (tendido de cables aéreos y/o subterráneo, despeje de luminarias, etc.); 8) prensa y difusión de las tareas desarrolladas.

A su vez resulta de suma necesidad complementar estas acciones mediante una participación activa en la plantación con instituciones educativas restableciendo el Día del Arbol y actividades anexas como así también de organismos que donen 0 cultiven ejemplares para ser ubicados en la vía pública. 


\section{Conclusión}

El árbol plantado ha finales del '20 o del '30 se ha desarrollado en un espacio público con exigencias totalmente diferentes a las que presenta hoy en día. Con la llegada del cableado aéreo, las luminarias bajas, la difusión masiva de los medios gráficos, el aumento del tránsito vehicular, la presencia de mayor señalización, el aumento poblacional, la generación de gran cantidad de residuos y de servicios, hizo que el espacio que se le había asignado quedase cada vez más reducido y en ciertos casos sacrificado según el uso que se le asignase.

Ahora bien plantar, reponer o eliminar árboles urbanos lleva a pensar bajo qué actitud se deberían llevar a cabo las intervenciones pertinentes. Si el arbolado de alineación ante todo es de dominio público, pero sin embargo el vecino interfiere positiva o negativamente como si fuera de su propiedad, resultando ser un legado de otra época cuando estorba, tapa la fachada, levanta la vereda o arroja hojas a la vía pública. Y si a su vez es el referente histórico del lugar que de una aparición espontánea, pasó a ser cultivado en el espacio privado de solares y chacras, para alinearse posteriormente en el paisaje modificado del espacio público, el cual responde a una ciclo de vida como todo ser vivo a diferencia del poste, el cable, el asfalto, la baldosa 0 el cesto.

La falta de planificación en lo que respecta a las tareas que sustenten un adecuado ordenamiento del arbolado de alineación se hizo extensible a lo largo de los años, a los cuales se le sumó: la falencia en la formulación y actualización de normativas acordes a la realidad, como reguladoras del accionar público y privado sobre los ejemplares presentes en las aceras de la ciudad y la carencia de campañas educativas de toma de conciencia sobre el paisaje urbano en el cual vivimos.
La necesidad de contar con estudios científicos de los ejemplares que aporten el conocimiento necesario para la detección de problemáticas y resolución de las mismas en las cuales la intervención vecinal organizada se sustente como una herramienta alternativa para el cause de la propuesta.

Por consiguiente no resulta ajeno decir en esta instancia que a partir del arbolado de alineación se crean situaciones conflictivas debido a que existen intereses contrapuestos de los actores sociales tanto en lo público cono en lo privado. Pero fue el objeto de este trabajo poder abordar una primera aproximación a la problemática de los árboles de alineación de Quilmes, para la cual el hombre desde su inserción interfiere en ellos en forma directa.

Sin más la degradación está presente y por diversas causas el ejemplar arbóreo se encuentra condicionado a funciones y sistemas que se interrelacionan en el mismo espacio público. Merecen nuestra atención buscar las alternativas necesarias y viables para que la comprensión y la planificación puedan conjugarse consensuadamente. El campo de acción resulta ser muy amplio e imprescindible el cual requerirá del trabajo profesional para despertar el interés de aquellos que posean la voluntad y la decisión para gestar cambios de actitud, para comprometerse y poder concienciar al otro que el paisaje urbano en el cual estamos inmersos merece una urgente y eficaz revalorización. Porque todo accionar necesita de cierto ordenamiento y porque es a partir del mismo donde podemos llegar a compartir y a defender lo que es de todos. 
CAMPARI, G.E. (2006) Proposal of ordering of the hoisted one of alignment by means of the local intervention in the Quilmes Party Province of Buenos Aires - Argentina. Revista do Departamento de Geografia, n. 19, p. 20-34.

Abstract: The public arborization of alignment is conditioned by diverse conflicts derived from the population growth, the real state interests and vehicular transit increase, the clandestine interventions, the normative breach, the questions of hygiene, the esthetic and its progressive natural deterioration. In such sense the present work has as purpose to delineate a first approach to the problematic of the trees in the sidewalks of streets and avenues of the city of Quilmes, for which the human factor is an agent of degradation of the urban landscape whose remarkable incidence is realized in the arborization, constituting an indicator of negative landscaping disturbance; which by means of a suitable planning and modifying this human attitude through the organized local intervention, would make possible to manage in permanent value this vegetal resource as public service, natural and cultural patrimony of the City.

Key words: Hoisted of alignment; Hoisted public; Urban landscape; Public service; Cultural patrimony; Local intervention.

Recebido em 01 de Novembro de 2005, aceito em 2 de outubro de 2006.

\section{Referencias}

ADOQUE (Asociación Bonsai de Quilmes) (1998) Relevamiento del arbolado de Quilmes, Dirección de Estudios del Territorio de la Municipalidad de Quilmes, inédito.

ALES, M. (1963) Plano Topográfico del Pueblo de Quilmes, Actualizado para 1890, (Escala no legible).

ALES, M (1968) Sintesis Histórica de Quilmes (1856-1966), Serie de Archivos y Fuentes de Información № 3, Municipalidad de Quilmes, Secretaría de Gobierno y Cultura, p. 7-69.

ARGENTINA. Instituto Nacional de Estadística y Censo (INDEC) (1991) Censo Nacional de población y vivienda 1991. Cap. 3 Comentarios sobre las principales características de la población y las viviendas de los barrios de la Capital Federal.

AUGE, M. (1996) Los "no lugares": Espacios del anonimato, Editorial Gedisa, Barcelona, p. 84.

BOTINNI DE BARUCCA, G. (1990) Metodología para proyectos con participación comunitaria, Buenos Aires, inédito, p. 3.

BUENOS AIRES (Provincia). Intendencia Municipal de Quilmes (1888) Legajo $N^{\circ} 30$.

BUENOS AIRES (Provincia). Intendencia Municipal de Quilmes (1898) Legajo No 8.

BUENOS AIRES (Provincia). (1917/18) Intervención Nacional de la Provincia de Buenos Aires, Memoria del Comisionado Municipal, Sr. José Augusto Otamendi, Imprenta Luchelli, Quilmes, p.126.

BUENOS AIRES (Provincia) (1946) Memoria y Balance Financiero, Ejercicio 1946, Comisionado Municipal Jesús Castro, Quilmes, p. 48.

BUENOS AIRES (Provincia). Intendencia Municipal de Quilmes (1953) Memoria, Ejercicio Administrativo 1953, Intendente
Pedro Bond.

BUENOS AIRES (Provincia). Municipalidad de Quilmes (1971) Boletín Municipal, Quilmes, p. 25.

CAMPARI, G. (2001) Propuesta de ordenamiento del arbolado de alineación Partido de Quilmes. Buenos Aires, 1 v. Tese (Trabajo de graduación) - Facultad de Agronomía, Universidad de Buenos Aires.

CAPEL, H. (1982) Las nuevas geografías, Editorial Salvat, Barcelona, p. 45.

CRAVIOTTO, J. (1966) Quilmes a través de los años, Municipalidad de Quilmes, Secretaría de Gobierno y Cultura, p. 39, 227 .

CHUECA GOITÍA, F. (1978) Breve Historia del Urbanismo, Editorial Alianza, Madrid, p. 129.

DOLLFUS, O. (1978) El análisis geográfico, Editorial Oikus-Tau, Barcelona, p.73.

DOLLFUS, O. (1990) El espacio geográfico, Editorial Oikus-Tau, Barcelona, p.39.

DUVERGER, M. (1996) Métodos de las ciencias sociales, Editorial Ariel S.A., Barcelona, p. 286.

LOMBAN, J. C. (1990) Nueva Historia de Quilmes, El Monje, Buenos Aires.

LYNCH, K.(1998) La imagen de la ciudad, Colección Punto y Línea, Editorial Gustavo Gili; Barcelona, p. 62.

PERSPECTIVA SUR (2000) Aseguran que es grave el deterioro del arbolado urbano, Quilmes18/1/2000, p. 5-6.

SANTOS, M. (1996) Metamorfosis del espacio habitado, OikosTau, Barcelona, p. 59-65.

TRAVERSI, M.; (1949) Estampas de Antaño, Editorial Librerías EI Ateneo, Buenos Aires, p. 12, 97. 